\title{
Viremic Blood Donor Found by a Rapid Screening Method in a Season of High Human Parvovirus B19 Activity in Niterói, Rio de Janeiro, Brazil
}

\author{
Sérgio Setúbal $/{ }^{+}$, Cláudia Alessandra da Silva Cárdias*, Solange Artimos de Oliveira, \\ Jussara Pereira do Nascimento*/**
}

Departamento de Medicina Clínica *Departamento de Microbiologia e Parasitologia, Universidade Federal Fluminense, Rua Marquês de Paraná 303, 24033-900 Niterói, RJ, Brasil **Departamento de Desenvolvimento Tecnológico,

Biomanguinhos-Fiocruz, Rio de Janeiro, RJ, Brasil

Erythrovirus $B 19$ infection is usually benign but may have serious consequences in patients with hemolytic anemia (transient aplastic crisis), immunodeficiency (in whom persistent infection can lead to chronic bone marrow failure with anemia), or who are in the first or second trimester of gestation (spontaneous abortion, hydrops fetalis, and fetal death).

Being non-enveloped, B19 resists most inactivation methods and can be transmitted by transfusion. B19 is difficult to cultivate and native virus is usually obtained from viremic blood. As specific antibodies may be absent, and there is no reliable immunological method for antigen detection, hybridization or polymerase chain reaction are needed for detecting viremia. A rapid method, gel hemagglutination (Diamed ID-Parvovirus B19 Antigen Test), can disclose highly viremic donations, whose elimination lessens the viral burden in pooled blood products and may even render them non-infectious. In order to obtain native antigen and to determine the frequency of viremic donors, we applied this test to blood donors in a period of high viral activity in our community. Positive or indeterminate results were re-tested by dot-blot hybridization. We tested 472 donors in 1998 and 831 ones in 1999. One viremic donor was found in 1999. We suggest that in periods of high community viral activity the gel hemagglutination test may be useful in avoiding highly viremic blood being added to plasma pools or directly transfused to patients under risk.

Key words: parvovirus B19, human - transfusion transmitted virus - mass screening - blood transfusion

Erythrovirus (formerly parvovirus) B19 and the novel Erythrovirus V9 are by now the only parvoviruses implied in human disease (Laub \& Strengers 2002). Their genomes consist both of single-stranded DNA molecules 5596 nucleotides long. They diverge by $11 \%$, mainly in the VP1 capsid gene (Nguyen et al. 1999, Laub \& Strengers 2002). There seems to be no cross immunity between them (Nguyen et al. 1999). Infection with Erythrovirus B19 (from now on referred as B19) causes erythema infectiosum (Anderson et al. 1983), a common childhood exanthematic disease which runs with asymptomatic and very transient pure red cell aplasia of the bone marrow (Anderson et al. 1985). In adults, especially in women, the infection tends to manifest itself as symmetrical arthropathy of the small joints of feet and hands (Brown 1997). Skin rash and arthralgia are believed to result from immune complex deposition (Brown \& Young 1997). Near 30\% of the infections are entirely asymptomatic (Brown 1997). The infection can be life threatening in patients suffering from chronic

Financial support: CNPq and Faperj. CAS Cárdias received a Faperj fellowship during this period.

${ }^{+}$Corresponding author. Fax: +55-21-2719.7262. E-mail:

labutes@attglobal.net.

Received 23 July 2003

Accepted 18 December 2003 hemolytic anemia (e.g., sickle cell disease), in whom the short life span of red blood cells often leads to severe anemia before the activity of the bone marrow starts again (Pattison et al. 1981). In immunodeficient patients, in whom the virus is not readily cleared, B19 infection may persist and cause long lasting pure red cell aplasia (Kurtzman et al. 1987). Infections occurring in pregnant women may result in severe intrauterine anemia leading to fetal hydrops and death (Brown et al. 1984).

B19 infection is common and $40-60 \%$ of adults have antibodies due to previous experience with the virus (Cohen \& Buckley 1988, Nascimento et al. 1990, Freitas et al. 1990, 1999). Immunity to the virus appears to be life long. Epidemiologically, rates of infection increase every 3-4 years (Serjeant et al. 1993), although longer cycles, with increases in viral activity occurring every 4-7 years (Rodis 1999), have also been described. B19 is usually spread by respiratory secretions, but can be transmitted transplacentally and by transfusion of blood or blood components (Laub \& Strengers 2002).

Transfusion with B19 contaminated blood or blood products may be a risk to non-immune pregnant women and to immunocompromised patients, insofar the latter are often multitransfused. In normal individuals with acute infection high level viremia can be detected for 4 to 5 days before the appearance of antibodies and onset of symptoms (i.e., the antibody-mediated rash and arthralgia) (Brown \& Young 1997). This explains why blood donors may be asymptomatic, despite levels of viremia up to $10^{12}$ 
genome equivalents (geq) per ml (Blümel et al. 2002). The subsequent onset of clinical disease in the donor rarely, if ever, leads to a proper investigation about the possibility of disease transmission during the foregoing donation. Being a non-enveloped virus, B19 is known to resist solvent and detergent (SD) inactivation treatments usually employed in blood and in blood products. Due to the present impossibility of eliminating the virus from these products, there is an urgent need of a method of mass screening for viremic blood donors. Despite the transient nature of both symptoms and high level viremia (as detected by dot-blot), low level viremia [only detected by polymerase chain reaction (PCR)] can persist for up to 6 months after acute infection. In these latter cases viruses are complexed with antibodies and are less capable of initiating infection in the recipient. The incidence of truly infective blood donors is therefore very low. Nevertheless, only one highly viremic donation may be sufficient to contaminate a plasma pool and result in final product contamination (Schmidt et al. 2001). Although it is less frequent, single donor blood components (e.g., platelets) can also transmit B19 infection (Cohen et al. 1997). In spite of this, blood donor units are not screened routinely for non-enveloped viruses such as B19 (Laub \& Strengers 2002). Screening by very sensitive tests like PCR may be impractical due to many false positive results related to low level (and less infective) viremia.

The frequency of B19 infected blood donations varies according to the sensitivity of the method used for the diagnosis and to the activity of the virus in the community. Detection of viremic blood donors may be very important, if blood and blood components are to be transfused in immunocompromised patients such as HIV-infected people or transplant recipients, in whom B19 infection can have serious consequences (Cohen et al. 1997, Hayakawa et al. 2002).

Studies on the frequency of viremic donors have already been done in Brazil. During 1988, in order to obtain viral antigen, Cruz and coworkers tested 6400 blood donations by counter-immuno-electrophoresis against a strongly anti-B19 IgG-positive human serum. They found one antigen positive donation, later confirmed by electron microscopy, radioimmunoassay with monoclonal antibodies, and dot-blot hybridization (Cruz et al. 1989). In 1996 Lisboa and coworkers reported a frequency of 1:4235 asymptomatic viremic donors, after having 46,587 donations screened by PCR during a period of one year (Lisboa et al. 1996).

B19 can be cultivated only in primary culture explants of human erythroid precursors, or in some continuous megakaryocytoblastoid cell lines. However, these systems are not suitable as a practical source of virus (Brown \& Young 1997). The resulting shortage of native viral antigen poses a problem in obtaining positive controls for laboratory tests. Empty viral capsids, obtained in insect cells through recombinant technology, can be employed in serologic assays (Pereira et al. 2001). However, whole viruses are necessary for positive controls in PCR, dotblot hybridization and antibody neutralization tests. Whole virus are hard to obtain and can be found only in acute phase clinical specimens or in donated blood.
The main objective was to determine the frequency of viremic donors in a period of high viral activity in the community employing a rapid and cheap gel hemagglutination test. The secondary objective was to obtain a supply of native infectious viral antigen.

\section{MATERIALS AND METHODS}

We applied the gel hemagglutination test (Diamed IDParvovirus B19 Antigen Test, Diamed S.A., Cressier, Switzerland) (Cohen et al. 1995, Hitzler \& Runkel 2002) in blood samples collected from non remunerated donors. The study was done in two different years (1998 and 1999), the second of them corresponding to a season of high viral activity in the community (Oliveira et al. 2002). The samples were obtained after informed consent from donors from the blood bank of Hospital Universitário Antônio Pedro (HUAP), Niterói, state of Rio de Janeiro, Brazil, and from Instituto Nacional de Câncer (Inca), Rio de Janeiro, state of Rio de Janeiro, Brazil.

The hemagglutination assay was done in gel tubes arranged in ID-cards (Fig. 1). Accordingly to the test manufacturer's instructions, supplied papain-treated test erythrocytes were centrifuged for $3 \mathrm{~min}$ at $3000 \mathrm{rpm}$. The supernatant was taken off and replaced with the same volume of supplied buffer. The pellet was then resuspended and agitated for $10 \mathrm{~min} ; 25 \mu \mathrm{l}$ of this suspension and $10 \mu \mathrm{l}$ of the donor's plasma were pipetted onto the sepharose gel in each tube, and the cards were centrifuged at low speed $(85 \mathrm{~g})$ for $10 \mathrm{~min}$. In this test, agglutinated erythrocytes remain on the surface of the gel, while free red cells go to the bottom. The results are easy to read and are classified as positive, negative or indeterminate.

All sera with positive or indeterminate results on gel hemagglutination were submitted to dot-blot hybridization using a biotin-labeled recombinant plasmid as B19

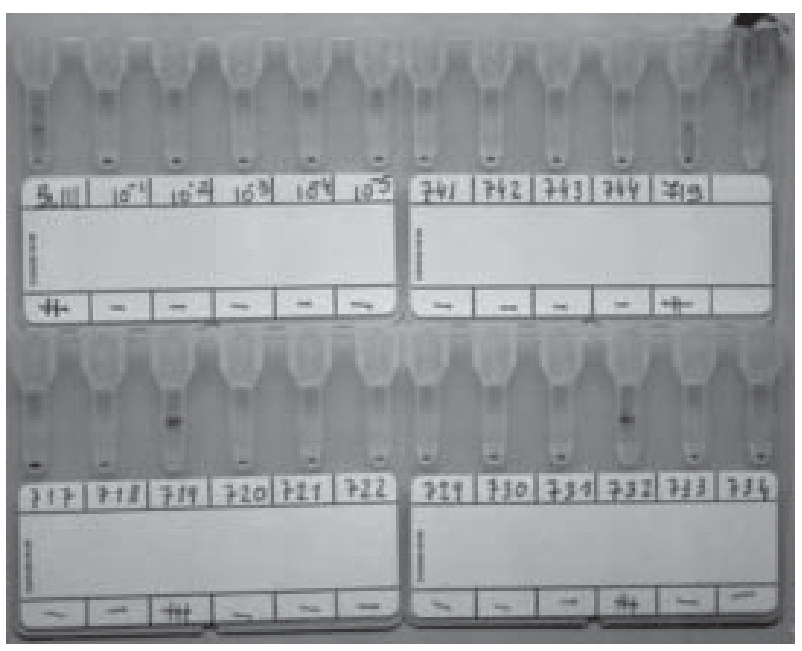

Fig. 1: gel hemagglutination test (Diamed ID-Parvovirus B19 Antigen Test). Top left, positive donor plasma BrIII (Cruz et al. 1989), undiluted and diluted up to $10^{-5}$. Bottom left and bottom right, seemingly positive tests (719 and 732) that gave equivocal results on repetition (top right for sample 719, not shown for sample 732). All other samples gave clearly negative results. 
specific probe and streptavidin-peroxidase to develop the hybrids, as described by Mori et al. (1989). Part of the sera collected in 1998 were joined in pools of ten sera each and tested by PCR, kindly performed by Fundação PróSangue/Hemocentro de São Paulo. Sera collected in 1999 were not submitted to PCR.

\section{RESULTS}

The first sampling period started on August 31 and ended on November 13, 1998. We obtained 496 samples from consecutive donors in the HUAP blood bank. From October 18 to December 8, 1999, additional samples were collected in the same blood bank from 522 consecutive donors. Between September 1 and November 8, 1999, more 529 blood samples were obtained from discarded blood bag connection tubes from Inca. All blood donors from HUAP blood bank were 18 or more years old, and $78 \%$ of them were men. Of all these samples, 1303 (472 obtained in 1998 from HUAP; 516 obtained in 1999 from HUAP; and 315 obtained in 1999 from Inca) were tested for B19 viremia by the Diamed gel hemagglutination. Of the 472 samples tested in 1998, two gave equivocal results in gel hemagglutination (Fig. 1). Five out of the 831 samples tested in 1999, all obtained in the HUAP blood bank, also tested indeterminate on gel hemagglutination. One more of these 1999 samples tested weakly positive, and another one strongly positive. All these nine plasma samples showing indeterminate or positive results were tested by dot-blot hybridization and only the strongly positive in gel hemagglutination was confirmed as positive by dot-blot (Fig. 2). This plasma sample was obtained on October 19 from a 26 years old female commercial employee; 288 of the 472 samples obtained in 1998 were also tested by PCR, with negative results.

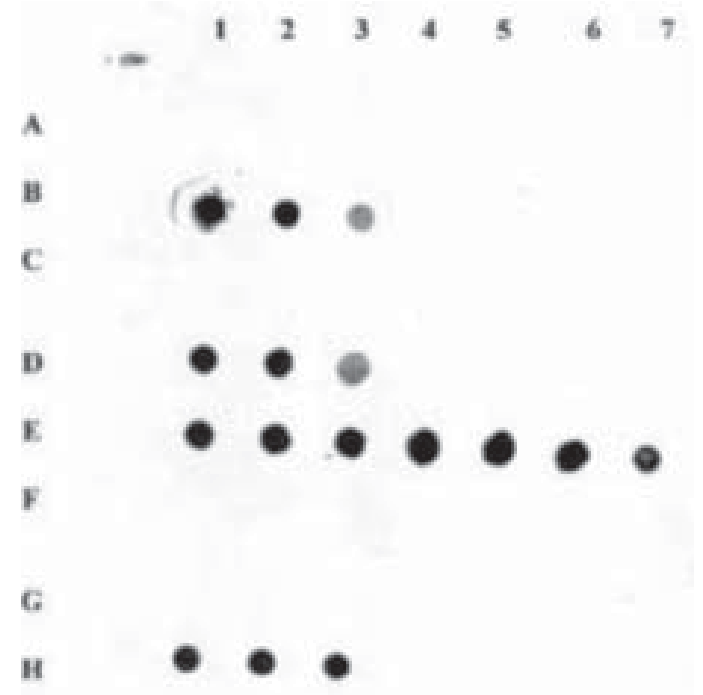

Fig. 2: dot-blot hybridization. B1-3, D1-3, and E1-3, samples from B19-DNA-positive patients (undiluted and diluted up to $10^{-2}$ ); H13 , positive donor plasma BrIII (Cruz et al.1989) (undiluted and diluted up to $10^{-2}$ ); E4-7, Diamed-positive donor plasma (undiluted and diluted up to $10^{-3}$ ); A1-3, C1-3, F1-3, and G1-3, samples from B19-DNA-negative patients (undiluted and diluted up to $10^{-2}$ ); A47, B4-7, C4-7, D4-7, and F4-7, Diamed-positive donor plasmas (undiluted and diluted up to $10^{-3}$ ).

\section{DISCUSSION}

Some blood derivates, e.g. Factor VIII, are prepared from plasma pools obtained from thousands of donors. Before being used, these plasma pools undergo virus inactivating purification procedures (e.g. solvent detergent treatment). As B19 is a small non-enveloped virus that is not affected by such purifying procedures, which are effective mainly against enveloped viruses, these methods are not sufficient to remove completely the virus from a possibly infected donated blood present in the plasma pool. These plasma pool are frequently (85\%) contaminated with B19 DNA (Hayakawa et al. 2002) and often contain more than one strain of B19, as demonstrated by DNA sequencing (Blümel et al. 2002). Even SD treated concentrates previously heated (in a lyophilized state) at $100^{\circ} \mathrm{C}$ for $30 \mathrm{~min}$ (Santagostino et al. 1994) can transmit B19 to susceptible patients. The presence of viral DNA does not necessarily means that plasma derivatives are still infectious. Whether or not B19 has been inactivated during their production cannot be ascertained directly through B19 isolation, as the virus grows only in differentiated erythroid progenitor cells and is therefore difficult to cultivate. Although added animal parvovirus can be used instead for ascertaining the efficacy of the purification method, no routine laboratory technique for testing B19 infectivity is presently available (Schmidt et al. 2001).

As already stated, both the sensitivity of the method used for the diagnosis and the activity of the virus in the community greatly influence the frequency of B19 infected blood donations. With techniques like PCR, the frequency of a viremic blood donation ranges from 1:167 (Santagostino et al. 1994, Yoto et al. 1995) to 1:1420 during seasonal outbreaks (Schmidt et al. 2001) and from 1:5950 to 1:30000 off-season (Cohen et al. 1990, McOmish et al. 1993, Schmidt et al. 2001).

The fact that $\operatorname{IgM}$ or IgG antibodies can be absent in highly viremic donations indicates that antibody screening will not be an effective strategy for reducing transmission by blood components (Hitzler \& Runkel 2002). There are no reliable immunological methods for detecting B19 antigen, but dot blot hybridization and PCR can detect viral DNA. A dot blot hybridization assay has a sensitivity of about $10^{7}$ viral genomes $/ \mathrm{ml}$ (Hicks et al. 1995). PCR can disclose viremia in concentrations as low as $2.4 \times 10^{4}$ copies of viral DNA per ml (McOmish et al. 1993). As PCR can detect nonfunctional DNA, the infectivity of plasma products that contain B19 DNA is unclear (Blümel et al. 2002). Early insensitive methods like counter current immuno electrophoresis and double immune diffusion seem to have been altogether abandoned.

As dot blot is less suitable to automatization and PCR is expensive and still impractical for large-scale use, alternative methods have been devised for mass screening. A receptor-mediated hemagglutination test $(\mathrm{RMH})$ takes advantage of the virus ability to bind to blood group $\mathrm{P}$ antigen on the surface of human erythrocytes (Sato et al. 1995, Hitzler \& Runkel 2002). This test can detect B19 at concentrations of $10^{5}$ to $10^{6}$ copies of viral genome per $\mathrm{ml}$, as verified by semi-quantitative PCR (Sato et al. 1995). Blood group O erythrocytes with $\mathrm{P}$ globoside in their sur- 
faces are readily agglutinated by viremic sera diluted in a low $\mathrm{pH}$ buffer. This is 10,000 to 100,000 times more sensitive than double immunodiffusion and 100 to 1000 times less sensitive than PCR (Sato et al. 1995). In a non-prevalent period, RMH detected viremia in 27 out of 45,735 blood donors' samples. None of the viremic donors could be detected by double immunodiffusion. Only seven of these viremic samples were confirmed by PCR (Sato et al. 1995). This gives RMH a specificity of $99.96 \%$. In contrast with PCR, which can detect inactivated or degraded virus, RMH detects only those virions that can bind to the receptor molecules on the erythrocytes employed in the test, i.e., infective virus (Cohen et al. 1995).

Hemagglutination assays can be run in gel tubes arranged in ID-cards (Cohen et al. 1995, Hitzler \& Runkel 2002), as performed in our study. Again, the test is based on the virus ability to bind to blood group P antigen on the surface of human erythrocytes, leading to their agglutination. In order to separate agglutinated and non agglutinated test red cells, the reaction mixture is centrifuged through a gel filtration matrix. The results are easy to read and are classified as positive, negative or indeterminate. Cohen et al. (1995), confirming ID-cards hemagglutination results with a dot blot hybridization assay, demonstrated for the gel agglutination an overall sensitivity of $79 \%$. This raised to $100 \%$ when only sera with more than $10^{11}$ or more genomes $/ \mathrm{ml}$, as determined by the hybridization assay, were employed (Cohen et al. 1995).

In another study (Sakata et al. 1999), conducted in Japan, hemagglutination was consistently positive in donations with PCR titers higher than $10^{7}$ or $10^{8}$, but gave inconsistent results in intermediate PCR titers and was negative in low PCR titers. However, the infectivity of this last group of donations may be considered low, as none of the recipients became B19-positive (Sakata et al. 1999). This is often assumed to be due to the presence of neutralizing antibodies in 40 to $60 \%$ of these donations, which were probably obtained late in the course of the infection (Hitzler \& Runkel 2002). The number of donations found positive in this study was $142 / 465,665$ donations (1:3279, or $0.033 \%)$. With PCR, more positive donations were found $(0.052 \%)$ (Sakata et al. 1999).

In a German study (Hitzler \& Runkel 2002) the Diamed gel agglutination test was positive in 255 of 28,972 donations $(1: 113)$. When the test was done in triplicate, the number of donors consistently positive dropped to 35 (1:827). There was no information in this study about the activity of the virus in the community. Four of the 255 positive samples were also positive by PCR. Of the four samples, three had B19 DNA concentrations above $10^{12}$ $\mathrm{geq} / \mathrm{ml}$. The fourth sample had a B19 DNA concentration of $2.1 \times 10^{3} \mathrm{geq} / \mathrm{ml}$, and its reactivity in the Diamed gel hemagglutination test was unexpected, as the manufacturer and the authors established sensitivity thresholds of $10^{8}$ and $10^{9}$, respectively (Hitzler \& Runkel 2002). This positive result was attributed to the presence of non-specific serum agglutinins. Of interest, the viremia was demonstrated by PCR to persist in low concentrations for more than a year in all four donors. This persistence was not detected by gel hemagglutination.
In our study, we found one B19 DNA positive sample among nine gel hemagglutination positive (one) or weakly positive (eight) samples, a higher proportion than that of Hitzler and Runkel (2002), which was four PCR positive samples among 255 gel hemagglutination positive or indeterminate ones. Their reported specificity was $99.1 \%$. In our study, the strongly positive sample was clearly distinguishable, in the Diamed cards, from the weakly positive samples. Unfortunately, specificity could not be calculated in our study, as dot blot testing was not done in our gel hemagglutination negative samples. Nevertheless, it can be deemed relatively high, as none of the 288 PCR negative samples obtained in 1998 tested positive or indeterminate on gel hemagglutination.

Although gel hemagglutination cannot detect all B19 positive donations, it would be a useful alternative assay for detecting donations with high titer B19 virus. Even if low titer donations are missed, the viral load and infectivity of plasma pools can be substantially reduced (Cohen et al. 1995). In spite its low sensitivity, and taking into account the cost of other tests, gel hemagglutination could be employed as a means of eliminating highly viremic individual donations, thus lessening the viral burden in pooled blood products. There is some evidence that pooled blood products can be rendered non-infectious even if only high viremic donations are eliminated during the donor screening process (Weimer et al. 2001). This test is rapid, cheap and easy to perform and therefore is well suited for mass screening of blood donors. It is also important that the method chosen to reduce the risk of transmission does not cause any delay to the release of short lived or labile components, such as platelet concentrates.

As stated above, the existence of seasonal outbreaks may have influence on the frequency of infected donors. The seasonal profile of B19 activity in Niterói area was described by Oliveira et al. (2002). Studying patients with exanthematic diseases, these authors found distinct peaks of B19 activity during a six year observation period, suggesting that the disease appears to cycle in approximately four or five years. Most part of viral circulation took place in the second semester and in the very beginning of the next year, a period of time which corresponds, in the geographical region, to late winter, spring, and early summer. This seasonal distribution remained the same even out of the high activity years. The second semester of 1999 corresponded to the highest viral activity detected in that study.

This may explain the relatively high frequency of donor viremia (1:831) found in our study in 1999, in an adult population (blood donors) most part already immune to B19. We suggest that in periods of high activity of the virus in the community the hemagglutination test could be useful in avoiding highly viremic blood being added to plasma pools or directly transfused to patients who have hemolytic anemias, immunodeficiency or who are pregnant.

\section{ACKNOWLEDGEMENTS}

To Dr Laércio de Melo, from Diamed Latino America, who supplied the Diamed test kits employed in this work and also helped us with invaluable suggestions to the final text. To Dr 
Wilson Baptista da Rocha, from Hospital Universitário Antônio Pedro Blood Bank, and Dr Maria da Conceição M Guadagnino, from Instituto Nacional de Câncer Blood Bank for their cooperation.

\section{REFERENCES}

Anderson MJ, Higgins PG, Davis LR, Willman JS, Jones SE, Kidd IM, Pattison JR, Tyrrell DAJ 1985. Experimental parvovirus infection in humans. J Infect Dis 152: 257-265.

Anderson MJ, Jones SE, Fisher-Hoch SP, Lewis E, Hall SM, Bartlett CLR, Cohen BJ, Mortimer PP, Pereira MS 1983. Human parovirus, the cause of erythema infectiosum (fifth disease)? Lancet 1: 1378.

Blümel J, Schmidt I, Effenberger W, Seiz H, Willkomnen H, Brackmann HH, Löwer J, Eis-Hübinger AM 2002. Parvovirus B19 transmission by heat-treated clotting factor concentrates. Transfusion 42: 1473-1481.

Brown KE 1997. Human parvovirus B19 epidemiology and clinical manifestations. In LJ Anderson, NS Young (eds), Human Parvovirus B19. Monographs in Virology, Vol. 20, Karger, Basel, p. 42-60.

Brown KE, Young NS 1997. Human parvovirus B19: pathogenesis of disease. In LJ Anderson, NS Young (eds), Human Parvovirus B19. Monographs in Virology, Vol. 20, Karger, Basel, p. 105-119.

Brown T, Anand A, Ritchie LD, Clewley JP, Reid TM 1984. Intrauterine parvovirus infection associated with hydrops fetalis. Lancet 2: 1033-1034.

Cohen BJ, Buckley MM 1988. The prevalence of antibodies to human parvovirus B19 in England and Wales. J Med Microbiol 25: 151-153.

Cohen BJ, Beard S, Knowles WA, Ellis JS, Joske D, Goldman JM, Hewitt P, Ward KN 1997. Chronic anemia due to parvovirus B19 infection in a bone marrow transplant patient after platelet transfusion. Transfusion 37: 947-952.

Cohen BJ, Field AM, Gudnadottir S, Beard S, Barbara JA 1990. Blood donor screening for parvovirus B19. J Virol Methods 30: 233-238.

Cohen B, Millar A, Schwind P 1995. Screening of blood donors for human parvovirus B19. Lancet 346: 1631.

Cruz AS, Serpa MJA, Barth OM, Nascimento JP 1989. Detection of the human parvovirus B19 in a blood donor plasma in Rio de Janeiro. Mem Inst Oswaldo Cruz 84: 279-280.

Freitas RB, Gusmão SRB, Durigon EL, Linhares AC 1999. Survey of parvovirus B19 in a cohort of pregnant women in Belém, Brazil. Braz J Infect Dis 3: 6-14.

Freitas RB, Wong D, Boswell F, de Miranda MF, Linhares AC, Shirley J, Desselberger U 1990. Prevalence of human parvovirus (B19) and rubellavirus infections in urban and remote rural areas in northern Brazil. J Med Virol 32: 203208.

Hayakawa F, Imada K, Towatari M, Saito H 2002. Life threatening human parvovirus B19 infection transmitted by intravenous immune globulin. British J Haematol 118: 11871189.

Hicks KE, Beard S, Cohen BJ, Clewley JP 1995. A simple and sensitive DNA hybridization assay used for the routine diagnosis of human parvovirus B19 infection. J Clin Microbiol 33: 2473-2475.

Hitzler WE, Runkel S 2002. Prevalence of human parvovirus B19 in blood donors as determined by a haemagglutination assay and verified by the polimerase chain reaction. Vox Sang 82: 18-23.
Kurtzman GJ, Ozawa K, Cohen B, Hanson G, Oseas R, Young NS 1987. Chronic bone marrow failure due to persistent B19 parvovirus infection. New Eng J Med 317: 287-294.

Laub R, Strengers P 2002. Parvovirus and blood products. Pathol Biol 50: 339-348.

Lisboa CP, Sáez-Alquézar A, Stewien KE, Chamone DF, Durigon EL 1996. Blood donors screening for parvovirus B19 using polymerase chain reaction. Programas e Resumos do VIII Encontro Nacional de Virologia da Sociedade Brasileira de Virologia, São Lourenço, p. 134.

McOmish F, Yap PL, Jordan A, Hart H, Cohen BJ, Simmonds P 1993. Detection of parvovirus B19 in donated blood: a model system for screening by polymerase chain reaction. J Clin Microbiol 31: 323-328.

Mori J, Field AJ, Clewley JP, Cohen BJ 1989. Dot blot hybridization assay of B19 virus DNA in clinical specimens. J Clin Microbiol 27: 459-464.

Nascimento JP, Buckley MM, Brown KE, Cohen BJ 1990. The prevalence of antibody to human parvovirus B19 in Rio de Janeiro, Brazil. Rev Inst Med Trop São Paulo 32: 4145.

Nguyen QT, Sifer C, Schneider V, Allaume X, Servant A, Bernaudin F, Auguste V, Garbarg-Chenon A 1999. Novel human erythrovirus associated with transient aplastic anemia. J Clin Microbiol 37: 2483-2487.

Oliveira SA, Camacho LAB, Pereira ACM, Faillace TF, Setúbal S, Nascimento JP 2002. Clinical and epidemiological aspects of human parvovirus B19 infection in an urban area in Brazil (Niterói City Area, Rio de Janeiro state). Mem Inst Oswaldo Cruz 97: 965-970.

Pattison JR, Jones SE, Hodgson J, Davis LR, White JM, Stroud CE, Murtaza L 1981. Parvovirus infections and hypoplastic crisis in sickle-cell anaemia. Lancet 1: 664-665.

Pereira RFA, de Paula WNS, Cubel RCN, Nascimento JP 2001. Anti-VP1 and anti-VP2 antibodies detected by immunofluorescence assays in patients with acute human parvovirus B19 infection. Mem Inst Oswaldo Cruz, 96: 507-513.

Rodis JF 1999. Parvovirus infection. Clin Obstet Gynecol 42: 07-120.

Sakata H, Ihara H, Sato S, Kato T, Ikeda H, Sekiguchi S 1999. Efficiency of donor screening for human parvovirus B19 by the receptor-mediated hemagglutinatyion assay method. Vox Sang 77: 197-203.

Santagostino E, Mannucci PM, Gringeri A, Azzi A, Morfini M 1994. Eliminating parvovirus B19 from blood products. Lancet 343: 798.

Sato Y, Takakura F, Kojima E, Fukada K, Okochi K, Maeda Y 1995. Screening of blood donors for human parvovirus B19. Lancet 346: 1237.

Schmidt I, Blumel J, Seitz H, Willkommen H, Löwer J 2001. Parvovirus B19 DNA in plasma pools and plasma derivatives. Vox Sang 81: 228-235.

Serjeant GR, Serjeant BE, Thomas PE, Anderson MJ, Patou G, Pattison JR 1993. Human parvovirus infection in homozygous sickle cell disease. Lancet 341: 1237-1240.

Weimer T, Streichert S, Watson C, Groner A 2001. High-titer screening PCR: a successful strategy for reducing the parvovirus B19 load in plasma pools for fractionation. Transfusion 41: 1500-1504.

Yoto Y, Kudoh T, Haseyama K, Suzuki N, Oda T, Katoh T, Takahashi T, Sekiguchi S, Chiba S 1995. Incidence of human parvovirus B19 DNA detection in blood donors. $\mathrm{Br} J$ Haematol 91: 1017-1018. 